Article

\title{
Environmental Assessment of Municipal Solid Waste by Two-Stage Plasma Gasification
}

\author{
Ana Ramos ${ }^{1}\left(\mathbb{D}\right.$, Carlos Afonso Teixeira $^{2}\left(\mathbb{D}\right.$ and Abel Rouboa ${ }^{1,2, *}$ \\ 1 INEGI-FEUP, Institute of Science and Innovation in Mechanical and Industrial Engineering, Faculty of \\ Engineering of the University of Porto, 4200-465 Porto, Portugal; aramos@inegi.up.pt \\ 2 CITAB, Centre for the Research and Technology of Agro-Environmental and Biological Sciences, \\ University of Trás-Os-Montes and Alto Douro, 5001-801 Vila Real, Portugal; cafonso@utad.pt \\ * Correspondence: rouboa@utad.pt; Tel.: +351-259-350-317; Fax: +351-259-350-356
}

Received: 10 October 2018; Accepted: 7 November 2018; Published: 1 January 2019

\begin{abstract}
Plasma gasification is a thermal treatment successfully applied to waste streams, especially for solid residues. It sets an upgrade to more common waste-to-energy (WtE) techniques as incineration or gasification, granting lower levels of pollutant emissions, less landfilled materials and higher conversion efficiencies and producer gas quality. A life cycle assessment (LCA) of plasma gasification for one ton of a defined stream of solid waste is presented and compared to the hypothetical outcomes of incineration, highlighting the need to implement such sustainable techniques rather than more polluting ones. CML 2001 methodology was applied, enabling the evaluation of eleven impact categories, all of them depicting avoided burdens for the environment. Enhanced efficiency and cleanliness were seen due to the plasma step and to the replacement of part of the electrical grid mix by the produced electricity. Plasma gasification presented an overall better performance than incineration, portraying savings in energy and material resources as well as lower emissions to freshwater. Additionally, lower amounts of air contaminants were seen as well as almost triple of the produced electricity.
\end{abstract}

Keywords: waste-to-energy; plasma gasification; sustainability; life cycle assessment

\section{Introduction}

Waste treatment is a hot topic nowadays, due to the massive population growth and the correspondent improvement of their way of living. The European Union has established well-defined waste management policies, promoting preventive and reducing measures to take control over the progressively increasing amounts of solid residues [1]. The actual waste regulatory system, which applies to all the member states of the European Economic Community, is supported by the Waste Framework directive, the Hazardous Waste directive and the Waste Shipment regulation support [1,2]. Waste has become a widespread energy source, continuously produced and depicting different complexities and compositions [3,4]. Under the European conditions, municipal solid waste (MSW) with heating capacity ranging from 7.2 to $14.9 \mathrm{GJ} /$ ton is considered a fuel, providing a noteworthy source of power [5]. Noticeably, this promotes technology developments in order to assure that large amounts of waste are managed in the most sustainable means, and additionally, that noxious emissions are kept within legal values [6]. Currently, thermal treatments are the most used methods to process several waste streams including MSW [7,8], biomass [9,10] or even mixtures of different residues [11,12]. Waste-to-energy (WtE) techniques afford a dual gain once they decompose debris while producing energy and other valuable assets, achieving a reduction of $70-80 \%$ in waste mass and $80-90 \%$ in waste volume [13,14]. Regardless of their energetic performance, most of these treatments, as combustion and incineration, show environmental damages such as dioxin and furans formation, heavy metals, 
besides ash and flue gases. These require further treatment units, turning the overall process more expensive and demanding $[4,15-17]$. To respond to these issues, plasma gasification depicts a highly viable alternative, once waste decomposition takes place at severely higher temperatures directly avoiding most of the hazardous emissions, as well as enhancing conversion efficiency [18,19].

Plasma technology has been in use for several decades, namely in the aerospace industry, steel industry and in metallic and ceramic production [20,21]. Recently, innovative adaptations to broader applications, such as environmental control [19,22], hazardous waste management [23,24] or even medicine [25], have become more and more available and established [26]. This was made possible due to the chemistry of plasma itself: once it refers to a state of matter where part of the gaseous atoms or molecules are in the ionized form, charged particles are able to not only interact with neighboring particles, but also to be influenced by an electromagnetic field created by the other charges [27]. The combination of these highly reactive species with severely high temperatures grants a special atmosphere favorable for waste treatment, since inorganic materials may melt more efficiently, and a cleaner syngas is achieved: high energy and carbon conversion efficiencies, which promote a higher quality syngas [28]. Ray et al. [18] reported the development of an advanced thermal treatment, where high temperatures decompose household and trade wastes, originating a producer gas (syngas, suitable for generating electrical power in gas engines) and a vitrified product. Different waste streams were tested and the conversion efficiencies attained with this technology were in the order of $93 \%$ for carbon and 85\% for energy. Based on the same technology, Taylor et al. [29] treated different waste streams (auto shredder residues and refuse derived fuel) and confirmed its ability to process highly heterogeneous samples with even superior conversion rates (values up to $98 \%$ for carbon and $94 \%$ for energy conversion). Buyn et al. [30] used thermal plasma to convert MSW into a harmless slag with a volume reduction up to $99 \%$, which is higher than a conventional incinerator. Additionally, the authors were able to meet the imposed legal requirements in terms of emissions, in a completely environment-friendly process. New opportunities and challenges for this technology have recently arisen, highlighting its main advantages as a promising way of reducing (or even eliminating) MSW disposal on landfills, alleviating greenhouse gas emissions and saving natural resources as well as occupied land [26,31].

A typical plasma unit consists of a feed system to manipulate the waste into the reaction chamber, one (or more) plasma torch in the reaction chamber (constituting the central point of the waste treatment) and adjacent pollution control devices as cyclones, water quenches and scrubbers for syngas cleaning. A plasma torch is the device that permits the conversion of electrical energy into thermal energy by generating an electrical arc between two graphite electrodes [24]. Several thermal plasma generator systems exist, all presenting a common feature: although temperature in the core of the torch is higher than in the marginal zones, the rapid reduction still converges to an average value that may reach thousands of ${ }^{\circ} \mathrm{C}[19,31]$. Usually, a secondary chamber is also required to hold the oxidation of the furnace gases before they pass through the cleaning units. Its operation results in the combustion of hydrogen and carbon monoxide in a temperature range where no hazardous by-products may be conceived. Auxiliary gases may be fed into the furnaces when necessary (for instance, air and steam to promote gasification reactions, propane and air to burn flue gas components). Besides the producer gas with known uses, a vitrified by-product mainly formed by quartz and feldspar (depending on the waste input) is obtained, which have further uses, such as construction material or input for the ceramic industry [13,18]. Moustakas et al. [24] described the development of a plasma gasification/vitrification demonstration unit for treating hazardous waste in Greece, highlighting that the amount of energy necessary to make it work depends directly on the waste chemical composition. Additionally, the authors showed that significant environmental gains were achieved, namely due to lower air emissions and to the vitrified slag inherent innocuity. Tang et al. [32] reported the first preparation of glass-ceramic foams from the vitrified product obtained by MSW plasma gasification, adding calcium carbonate and sodium borate. 
In the waste treatment facilities, plasma gasification may be viewed as a single stage operation (only thermal plasma is used for the waste conversion) or as a two-stage process, where gasification produces raw syngas, and plasma acts as a gas treatment step [18,33]. Detailed insights on gasification (type of reactors, chemical reactions, syngas utilization, energy production, etc.) and its contribution as a sustainable WtE technique can be found elsewhere [34]. This two-stage plasma treatment is preferred over the single stage, in order to limit the high electric demand required to treat the whole sample of waste when compared to the decomposition of only tar and minor contaminants [35]. This also aids in overcoming drawbacks, such as relatively low outputs, poor control over the release of volatile compounds and tars, and low conversion efficiency [31]. Usually, by resourcing to gasification as a first conversion step, experimental conditions may be sharply optimized according to the specific waste stream. Likewise, this enhances the results achieved in the plasma refinement and the general performance of the two-stage approach. The two-stage configuration allows more efficient carbon conversion and higher quality syngas, mostly due to the further conversion of tars and chars into carbon monoxide and methane in the plasma converter [35]. Furthermore, an oxygen-deprived environment promotes low yields of syngas and higher amounts of vitrified slag, controlled amounts of steam and oxygen, which supports the achievement of the desired ratio of these two products. This helps to improve the industrial efficiency of the overall process, and additionally, promotes an easier scale-up of the initial experiments, although at least one exception could be drawn [36]. Still, in a comprehensive review, Ducharme compiles the major industrial plasma resources used in WtE and points out the exclusive development of a specific unit that allows the direct and effective plasma gasification of MSW, affording a high-quality syngas [37]. Ruj and Ghosh [36] suggested microwave induced plasma as the future approach to take in account for MSW treatment, as it demands less electrical power and bears broader ranges of moisture values, in some cases contributing to an enhanced efficiency of the WtE technology.

Besides economic or industrial efficiency, environmental assessment is a very important task to perform within waste management methodologies, as they provoke emissions to Nature and also consume (directly or indirectly) natural resources [38]. To achieve that mission, life cycle analysis is a powerful tool that allows the quantification of environmental impacts caused throughout the process, from waste reception through its treatment and disposal of remnant phases [39,40].

Despite its benefits, plasma gasification is still a step behind other waste management treatments regarding massive application, due to some drawbacks in the utilization of the existing facilities as well as the need for high level technology to produce reliable plasma arcs [36]. Hence, few reports on life cycle assessment (LCA) for solid waste plasma gasification are available; more studies and experiments on plasma gasification are required to gradually establish this technique as steadier within the other WtE and evidence its added value. Enforcement of these technologies by legislation or governmental imposition may be seen as a way of making policy makers and general population aware of the advantages they preconize, in order to enhance the acceptance and the developments achieved with this type of WtE treatments, to promote its progressive utilization instead of less ecological practices [41,42].

Therefore, the goal of this paper is to assess the life cycle impacts of the two-stage plasma gasification of a well-characterized sample of municipal solid waste, resuming its environmental impacts, as calculated through LCA methodology. In order to assess the latent environmental impacts triggered by MSW plasma gasification, an inventory of inputs and outputs was settled for the treatment of one ton of MSW. This will allow a prediction of possible process changes in case some of them depict injurious results. Therefore, establishing the system, the scope, the limits and the functional unit is of vital importance, since these may significantly influence the results. Detailed related emissions, as well as each process contribution to the final results, were reported in order to tackle which environmental compartments benefit more from this $\mathrm{WtE}$ technique. A comparison to a standard incineration scenario was conducted in terms of environmental performance and efficiency, enforcing the utilization of this technique rather than more polluting ones. 


\section{Methods}

\subsection{Scope}

The scope of this study was the analysis of the environmental impacts caused by two-stage plasma gasification. In this technique, data was modeled by a product sustainability software (GaBi-database version 4.131 distributed by PE International (Leinfelden-Echterdingen, Germany) [43]), which enabled the environmental assessment of the plasma gasification process. This was performed to evaluate 11 different impact categories through CML 2001 methodology [44]. This is an impact assessment method developed by the Institute of Environmental Sciences from the Leiden University, which applies quantitative modeling to early stages in the cause-effect chain, resourcing to a database that contains characterization factors for life cycle impact assessment categories. Table 1 shows the environmental indicators used and their correspondent units.

Table 1. Environmental indicators and its units.

\begin{tabular}{cc}
\hline Impact Factor & Units \\
\hline Abiotic Depletion Potential (ADP elements,fossil & $\mathrm{kg} \mathrm{Sb}$-equiv.; MJ \\
Acidification Potential (AP) & $\mathrm{kg} \mathrm{SO}_{2}$-equiv. \\
Eutrophication Potential (EP) & $\mathrm{kg} \mathrm{PO}_{4}$-equiv. \\
Global Warming Potential (GWP) & $\mathrm{kg} \mathrm{CO}_{2}$-equiv. \\
Freshwater Aquatic Ecotoxicity Potential (FAETP) & $\mathrm{kg} \mathrm{DCB-equiv.}$ \\
Human Toxicity Potential (HTP) & $\mathrm{kg} \mathrm{DCB-equiv.}$ \\
Marine Aquatic Ecotoxicity Potential (MAETP) & $\mathrm{kg}$ R11-equiv \\
Ozone Layer Depletion Potential (ODP) & $\mathrm{kg}$ ethene-equiv. \\
Photochemical Ozone Creation Potential (POCP) & $\mathrm{kg}$ DCB-equiv. \\
Terrestrial Ecotoxicity Potential (TETP) &
\end{tabular}

A detailed description for each category can be found elsewhere [45].

Within the assessed $\mathrm{WtE}$, two-stage plasma gasification consists of applying a plasma treatment step to the gaseous product coming from the gasifier. The complex organics in the raw syngas are cracked into a cleaner syngas, with tars being decomposed and efficiently converted. This makes a better usage of the oxygen introduced in the system to grant the endothermic reactions, while the power required by the plasma electrode is assured by the heat released in the exothermic reactions in the gasifier.

\subsection{System Boundaries and Functional Unit}

Four major processes are comprised in the system herein studied: MSW gasification (first stage), plasma (second stage), syngas treatment and landfill of the inert products. After the waste fraction is conveyed to the gasification chamber, its decomposition occurs in a bubbling fluidized bed through the controlled action of oxidant agents (oxygen and steam), producing syngas at high temperatures. Subsequently, this raw syngas and the ash produced during gasification are sent to the plasma unit where all the particles are captured and vitrified due to the severely high temperatures. After cooling the hot syngas, it flows through the cleaning units where it is conveniently treated so as to eliminate the remaining air pollutants. Harmful compounds are neutralized and drained from the system; the resulting inert residues are removed from the facility and landfilled.

Figure 1 describes the limits of the system, slashed lines indicating the boundaries. Colored boxes represent the processes, which are connected by flows (arrows). MSW was taken as an input as received at the plant, its origin, collection and transport to the thermal treatment facilities being excluded from the boundaries of the system, as well as metallic scrap regeneration. The power generated upon the two-stage plasma gasification of MSW replaced the electricity from the grid, in an auto-consumption mode, herein shown by the upper route (green, electricity flow). 


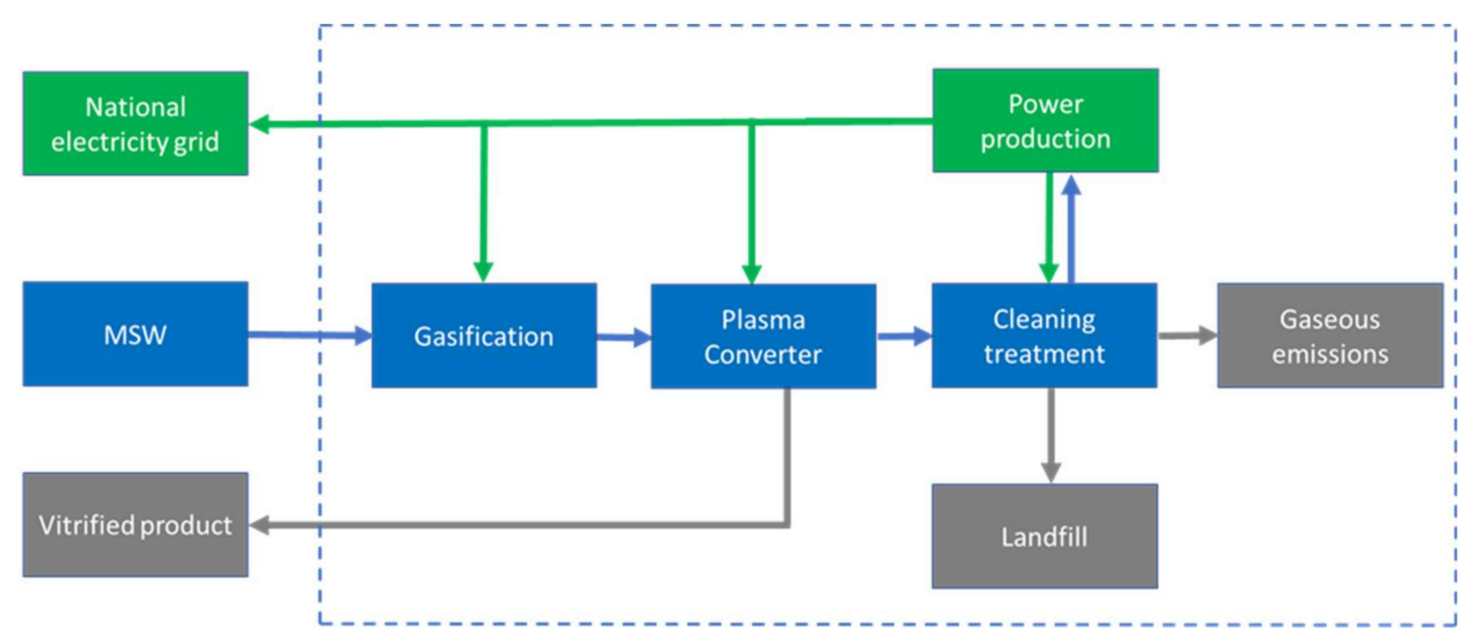

Figure 1. System limits within the plasma gasification assessed in this study.

The central route (blue) refers to the MSW path within the system, from its entrance to the gasification chamber, moving towards the plasma torch and further gas cleaning (material flow). The lower route (grey) represents the potentially hurtful outputs of MSW two-stage plasma gasification as well as the by-product formed in the plasma converter (vitrified slag), which can be sold to construction or ceramic companies. The functional unit (FU) was defined as 1 ton of MSW received at the plant, its characterization being shown in Figure 2.

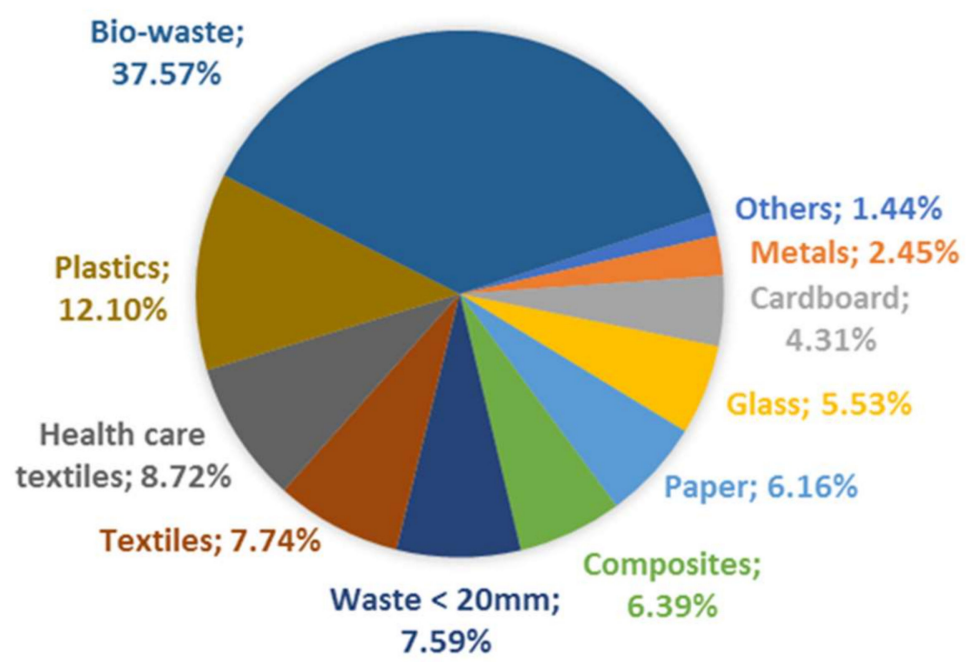

Figure 2. Global municipal solid waste characterization for the sample used in this study.

The selected feedstock presented a lower heating value (LHV) of $9 \mathrm{GJ} /$ ton and a moisture level of $40 \%$. Therefore, although drying pre-treatment was required in order to reduce the humidity of the sample and the energy necessary to process it [46], its energy content was promising regarding energetic valorization, as stated in the energy reports published by the Confederation of European Waste-to-Energy Plants [5].

For the implementation of LCA in GaBi software version 4.131 distributed by PE International (Leinfelden-Echterdingen, Germany), the following assumptions and hypothesis had been considered in the presented models:

(a) experimental data is representative of this type of $\mathrm{WtE}$ and waste stream, being reproducible;

(b) the electricity grid mix considered was the EU-28, composed as reported by Eurostat [47]; 
(c) data for the hypothetical incineration scenario was directly taken from the software database, with all the inner assumptions that a standardized European plant includes, as stated in Supplementary Material;

(d) the electrical grid is capable of receiving and distributing the produced electricity to consumers.

\subsection{Life Cycle Inventory}

An overall plan is composed by processes, which are interconnected by flows so that the modeling software performs the environmental impact calculations based on the actual scenario proposed for the experiment. This way, specific balances between the inputs and the outputs refer exactly to each process, based on the main operational data which are listed in the life cycle inventory, reported in Table 2.

Table 2. Main lifecycle inventory for the studied system.

\begin{tabular}{cc}
\hline Inputs and Outputs Per Ton of Municipal Solid Waste (MSW) \\
\hline Water, $\mathrm{kg}$ & 583.81 \\
Oxygen, $\mathrm{kg}$ & 236.70 \\
Nitrogen, $\mathrm{kg}$ & 33.22 \\
Sulphuric acid, $\mathrm{kg}$ & 3.53 \\
Sodium hypochloride, $\mathrm{kg}$ & 11.68 \\
Sodium hydroxide, Kg & 1.86 \\
Energy, MJ & 190.95 \\
Produced electricity, MJ & 3021.59 \\
Electricity exported to the National grid, MJ & 2830.64 \\
Air pollution control residues, kg & 15.10 \\
Removed scraps, kg & 28.90 \\
Landfilled slags, kg & 9.79 \\
\hline
\end{tabular}

Besides the vitrified product shown in Figure 1, another by-product is produced during the plasma gasification of MSW: steam. However, this output was not considered for the life cycle assessment once it is used to refuel the system, in the units where steam is supplied. Besides the producer gas, electricity was the major produced asset, as can be seen in Figure 3 which presents the established plan for this research.

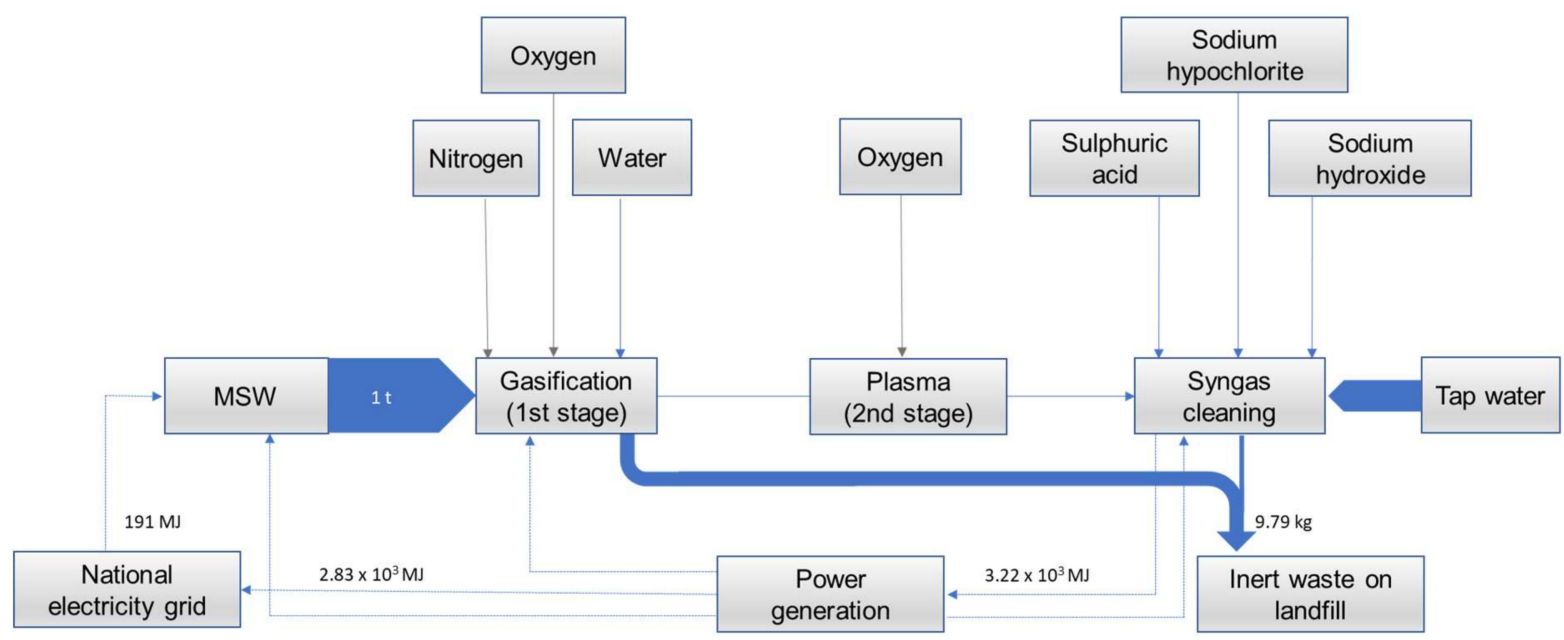

Figure 3. Two-stage plasma gasification plan for the present life cycle assessment (LCA) study.

As seen in the presented flowchart, gasification, plasma converter and syngas cleaning processes make use of auxiliary materials, while the produced electricity has two purposes: supplying the gasification facilities and also selling the excess to the national grid. 


\section{Results and Discussion}

To obtain the impacts caused by one ton of MSW, balances and flows were adjusted accordingly, so that the sustainability software could assess the environmental performance of the designed plan. The four main processes were intensively explored so that each flow could perfectly match the corresponding inputs and outputs, furthermore enabling the contribution to the adequate impact category to be established.

After all the balances and contributions were stated, a comparison of the obtained results to other studies was performed, albeit limitations as distinct system boundaries, functional units or assessment methodologies might have hampered its interpretation [48].

\subsection{Environmental Impacts from Two-Stage Plasma Gasification}

After setting-up the plan in GaBi and introducing the experimental data in CML 2001, each environmental indicator resulted in a quantified impact category, as shown in Table 3. The methodology includes a characterization factor that reflects the relative contribution of each substance to the dedicated environmental impact. This quantifies the influence of the substance in each impact category. In the case of waste management studies, positive values depict harmful impacts to the environment, meaning the grieving of natural resources or the emission of contaminants, whilst negative values represent environmental credits, or avoided burdens.

Table 3. Environmental results for the impact categories assessed during municipal solid waste (MSW) two-stage plasma gasification.

\begin{tabular}{|c|c|}
\hline Impact Categories & Environmental Quantities \\
\hline Global Warming Potential & $-31 \mathrm{~kg} \mathrm{CO} \mathrm{CO}_{2}$ eq. \\
\hline Eutrophication Potential & $-1.55 \times 10^{3} \mathrm{~kg} \mathrm{PO}_{4}{ }^{3-}$ eq. \\
\hline Acidification Potential & $-39.7 \times 10^{-2} \mathrm{~kg} \mathrm{SO}_{2} \mathrm{eq}$ \\
\hline Ozone Depletion Potential & $-2.13 \times 10^{-8} \mathrm{~kg}$ R11 eq. \\
\hline Abiotic Depletion Potential elements $_{1}$ & $-1.62 \times 10^{-5} \mathrm{~kg} \mathrm{Sb}$ eq. \\
\hline Abiotic Depletion Potential fossil $_{\text {f }}$ & $-382 \mathrm{MJ}$ \\
\hline Freshwater Aquatic Ecotoxicity Potential & $-6.41 \times 10^{-2} \mathrm{~kg}$ DCB eq. \\
\hline Marine Aquatic Ecotoxicity Potential & $-2.14 \times 10^{5} \mathrm{~kg} \mathrm{DCB}$ eq. \\
\hline Terrestrial Ecotoxicity Potential & $-2.95 \times 10^{-2} \mathrm{~kg}$ DCB eq. \\
\hline Human Toxicity Potential & $-14.7 \mathrm{~kg}$ DCB eq. \\
\hline Photochemical Ozone Creation Potential & $-2.23 \times 10^{-2} \mathrm{~kg}$ ethene eq. \\
\hline
\end{tabular}

As may be seen from Table 3, the assessed plan for plasma gasification held in this research gave rise to negative values for all the environmental categories. These are very promising results, as they contribute to the alleviation of the environmental burdens associated with the resources required by the thermal technique. As the two-stage plasma gasification is a recent application of plasma technology, there are not enough thorough studies on MSW disposal to enable a complete comparison of each environmental category. Therefore, a detailed portrayal of the respective emissions is further shown.

In an extended description, Figure 4 depicts the relation between each impact category and the respective environmental emissions. Carbon dioxide is the major avoided emission contributing to global warming potential (GWP), with a small role of methane (less than $5 \%$ of the total share). Published literature reports higher GWP impacts for similar waste streams and assessments [49]; Evangelisti et al. accounted the differences for biogenic $\mathrm{CO}_{2}$ inclusion and exclusion [50]. The results for eutrophication potential (EP) and acidification potential (AP) were $-1.55 \times 10^{3} \mathrm{~kg} \mathrm{PO}_{4}{ }^{3-}$ eq. and -39.7 $\times 10^{-2} \mathrm{~kg} \mathrm{SO}_{2}$ eq., respectively; inferior results for $\mathrm{EP}$ (approximately $-0.04 \mathrm{~kg} \mathrm{PO}_{4}{ }^{3-}$ eq.) and slightly better for $\mathrm{AP}$ (approximately $-1 \mathrm{~kg} \mathrm{SO}_{2}$ eq.) have been reported elsewhere [50], recalling that factors such as small differences in MSW composition can promote these differences. These differences are in the basis for the emissions herein seen, $\mathrm{EP}$ being dominated by $\mathrm{NO}_{x}$ emissions ( $>95 \%$ of the total share) while $\mathrm{AP}$ is mostly due to $\mathrm{SO}_{2}$ emissions (roughly $65 \%$ of the total share), besides $\mathrm{NO}_{\mathrm{x}}$ contribution. 
Applying the necessary proportion factor, worse values for EP $\left(1.4 \times 10^{-4} \mathrm{~kg} \mathrm{PO}_{4}{ }^{3-}\right.$ eq. $/ \mathrm{kg}$ of MSW $)$ and similar values for AP $\left(-9.71 \times 10^{-4} \mathrm{~kg} \mathrm{SO}\right.$ eq. $/ \mathrm{kg}$ of MSW $)$ were also reported [49]. In the case of ozone layer depletion potential (ODP), dichlorotetrafluoromethane (R114) is the chief emission, accounting for almost 100\% of the total share, as shown in Figure 4. Notwithstanding, the result for abiotic depletion of elements is small $\left(-1.62 \times 10^{-5} \mathrm{~kg} \mathrm{Sb}\right.$ eq.); its negative value may be associated to the enforcement of the renewable energies share in the national electricity mix, in this case avoiding the ablation of uranium. As far as abiotic depletion potential (ADP) fossil is concerned, it is possible to observe that each ton of MSW treated saves more than $380 \mathrm{MJ}$ of energy mainly due to the avoided expenditure of non-renewable resources, as stated by other authors [49]. In this case, these are mainly hard coal, natural gas, lignite and crude oil in descending order of shares.

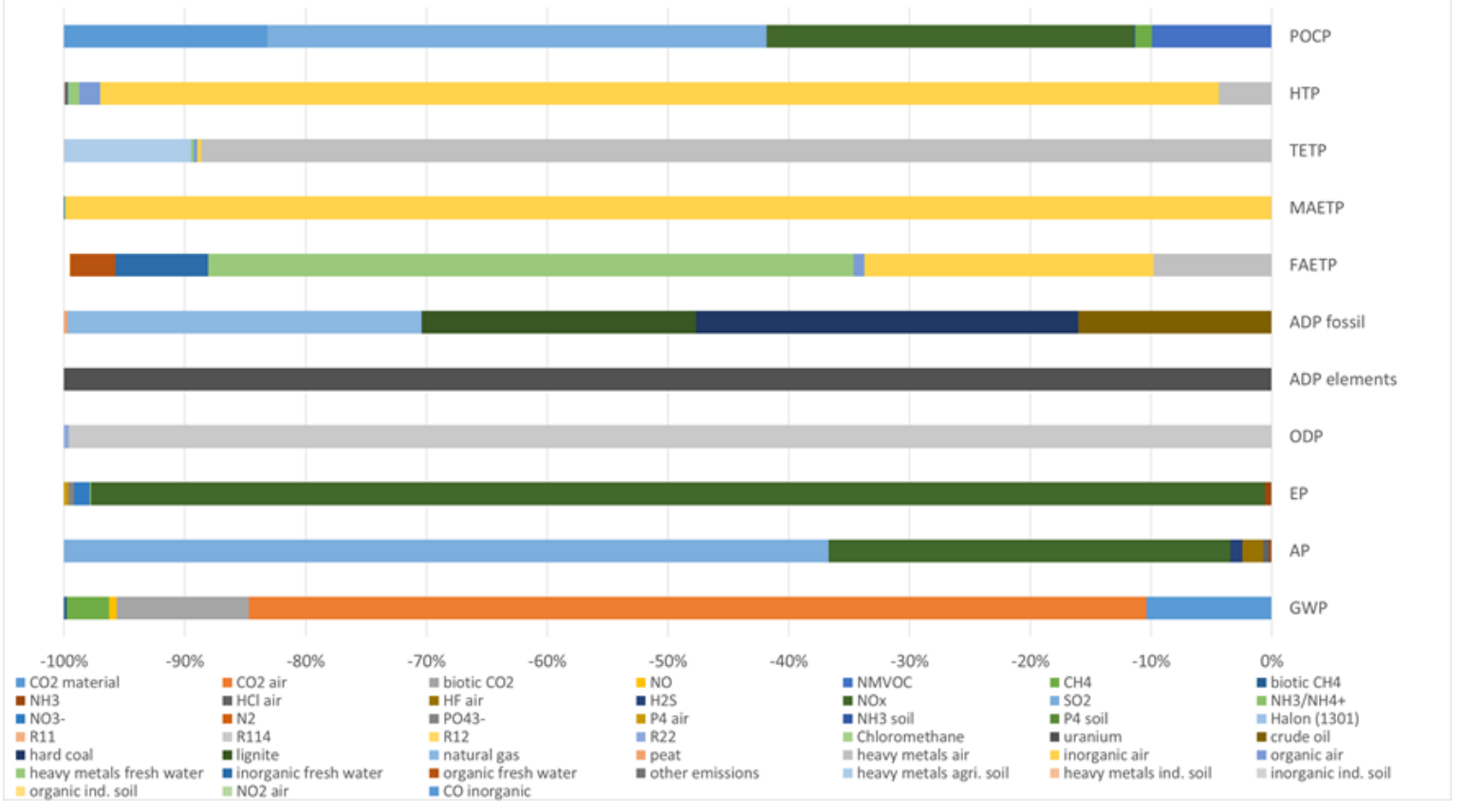

Figure 4. Impact categories and related emissions, for the two-stage plasma gasification of 1 ton of municipal solid waste (MSW).

Relative to the ecotoxicity categories, the results are explained by the proficiency attained with plasma conversion as well as the primary resources used in the production of the auxiliary materials commonly utilized for syngas cleaning in other thermal treatments are saved. In the case of freshwater aquatic ecotoxicity potential (FAETP), the most prevented hazard is the emission of heavy metals to freshwater, while for marine aquatic ecotoxicity potential (MAETP), this refers to the emission of various inorganic substances to air. For terrestrial ecotoxicity potential (TETP), the release of heavy metals to air and to agricultural soil constitutes the major environmental savings. FAETP and TETP results are somehow better than the ones achieved by Evangelisti et al. [50]. Additionally, as the raw syngas achieved before the final steps was already cleaner than that obtained from other WtE techniques, lower amounts of chemicals were disposed [49]. Regarding human toxicity, landfilling of reduced amounts of inert matter also highlights the good result for this indicator. With the necessary adjustment of the functional unit it relates to, the human toxicity potential (HTP) value reported by other authors seems to be a bit better (roughly $-40 \mathrm{~kg}$ DCB eq.) than the one achieved in this assessment for a similar strategy ( $-14.7 \mathrm{~kg}$ DCB eq.) [49]. Photochemical ozone creation potential (POCP) results show a major contribution from the syngas cleaning step, as most of the prevented emissions (nitrogen oxides and sulphur dioxide) refer to substances that generate precursor gases, potentially ending up in more ozone. Although the POCP value attained in this study is environmentally beneficial $\left(-2.23 \times 10^{-2} \mathrm{~kg}\right.$ ethene eq.), somewhat better results have been published 
elsewhere $\left(-8.6 \times 10^{-2} \mathrm{~kg}\right.$ ethene eq.) $[49,50]$. This is explained by the inclusion of a by-product within the boundaries of the referred studies, a secondary aggregate which will replace the need to produce primary aggregate from natural rock, constituting an avoided burden.

As herein seen, the two major causes for the avoided emissions in each impact category are the efficiency attained in the plasma conversion/cleaning step and the electricity production accomplished by the overall technique. Indeed, for categories such as EP and AP, the plasma converter reduces significantly the release of substances with surfactant and acid behavior, respectively, as these are mainly excreted during the syngas treatment in less advanced techniques, thus being severely reduced in the case of plasma gasification; in the case of the ecotoxicity categories, both aquatic (freshwater and marine water) and terrestrial reservoirs are kept from the hazardous emissions, while for HTP, the emission of inorganics is reduced; for POCP, most of the prevented emissions (nitrogen oxides and sulphur dioxide) refer to substances that generate precursor gases, potentially ending up in more ozone. Nonetheless, for GWP and ADP fossil, the electricity generation is the predominant factor reducing the consumption of fossil fuels, and contribute to a reduced release of $\mathrm{CO}_{2}$, as it is further introduced in the system, preventing the use of national grid mix, which is roughly composed by more than $40 \%$ of fossil fuels $[49,51]$.

\subsection{Process-by-Process Performance}

As seen, different processes influence distinct impact categories throughout the two-stage plasma gasification. As said before, the four chief processes that govern the overall waste treatment are MSW gasification (first stage), plasma converter (second stage), syngas treatment and landfill of the inert products. Figure 5 portrays a quantitative evaluation of their individual performance, a clarification on the case of landfill being shown for visual purposes.

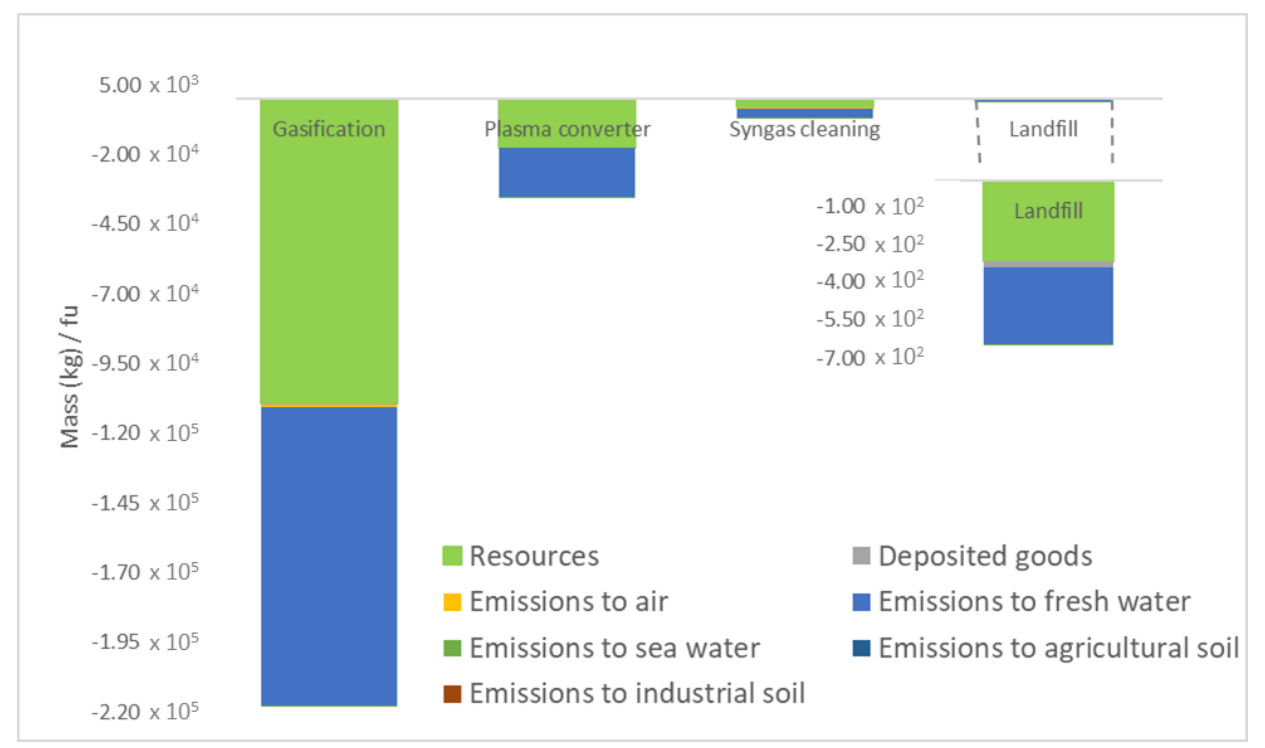

Figure 5. Contribution of the main processes to the global performance of two-stage plasma gasification as waste treatment technique (quantities per ton of treated MSW).

As shown in the previous section, all the CML 2001 impact categories depicted negative values for the plasma gasification of one ton of municipal solid wastes. Thus, by plotting the overall performance of each of the processes a coherent observation can be done: all of them showed results below zero. This means that all the processes are concomitant to an environmentally sound technique, even more enhanced by the evidenced "self-consumption" of the electricity generated within the system. Resources and emissions to freshwater are the dominant flows, a contribution of almost $50 \%$ of each being observed in the four processes. In total, each ton of MSW permits the saving of more than 260 tons of combined flows, water constituting the leading resource saved. Regarding the narrow section 
corresponding to emissions to air, organic substances, such as nitrogen compounds, carbon monoxide and oxygen, are the top emissions. It is important to notice that the minimum residence time of two seconds for combustion of gaseous products of non-hazardous wastes at $850{ }^{\circ} \mathrm{C}$ and for the gaseous outputs of hazardous streams at $1100{ }^{\circ} \mathrm{C}$ is required by Directive $2000 / 76 / \mathrm{EC}$ so as to reduce these compounds to values below legal limits [52].

Observing the general magnitude of each process to the overall environmental profile of the two-stage plasma gasification, it can be seen that gasification depicts the higher avoided burdens, followed by the plasma converter, the treatment step and lastly, landfill. This behavior is probably due to the high electricity demand during gasification step, which by self-supply of the system itself enables upgraded environmental credits at this stage. As the cycle evolves towards the production of a cleaner syngas, each step requires less resources and releases even less pollutants once the cleaning systems receive lower flows to treat, eventually ending in a markedly reduced amount of inert material sent to landfill due to the virtually non-existent yield of fine ash and air pollution control residues [31]. This is also shown by the small grey portion on landfill results, which corresponds to deposited goods, such as particulate matter, inert slags and ashes. Ray et al. [18] demonstrated the efficiency of the plasma to crack and reform tars, as well as other condensable species (namely hexane, toluene and phenol) normally found in the raw syngas leaving the gasifier. The high levels of these substances in raw syngas are effectively reduced by the plasma torch, reaching concentrations three orders of magnitude lower. This may be explained not only by the temperature effect on these substances and benzene concentration becoming negligible at $1030^{\circ} \mathrm{C}$, but also by the plasma geometry and energy density. Plasma configuration and high energy density accomplish an optimal fluidization of the molten slag arriving at the torch, capturing any solid particle. For a deeper understanding of the plasma action and possible parameter variations that will influence syngas composition, interesting conclusions were drawn by Materazzi et al. [35], who developed a model to predict syngas yield and composition for the two-stage plasma gasification of different mixtures of waste streams. Simulation results were compared to experimental data from an actual WtE plant, deviations of 3-6\% being explained based on the assumptions made throughout the model conception. Additionally, the authors compared a single stage process to the two-stage option and reported a complete carbon conversion in the second case, the arc power assuring the char decomposition. A clear downgrade in the process efficiency is seen as well when the plasma converter is switched off.

\subsection{Comparison to Conventional Incineration}

After the discussion of the two-stage plasma gasification results for this study, a brief comparison with a typical incineration scenario was performed, resourcing to a well-defined plan from the GaBi database (see Supplementary Material for details). This representative scenario simulates the incineration of one ton of average European MSW, modeling inputs, outputs and respective flows of a standardized European plant, as defined in the software [43].

\subsubsection{Environmental Performance Comparison}

The aim of this comparison was to explore the main differences in terms of environmental performance between a more conventional thermal treatment (incineration), highly used nowadays, and a promising upgrade technology (plasma gasification). Figure 6 portrays the comparative assessment, a detailed insight on the case of incineration being shown for better interpretation of the results. 


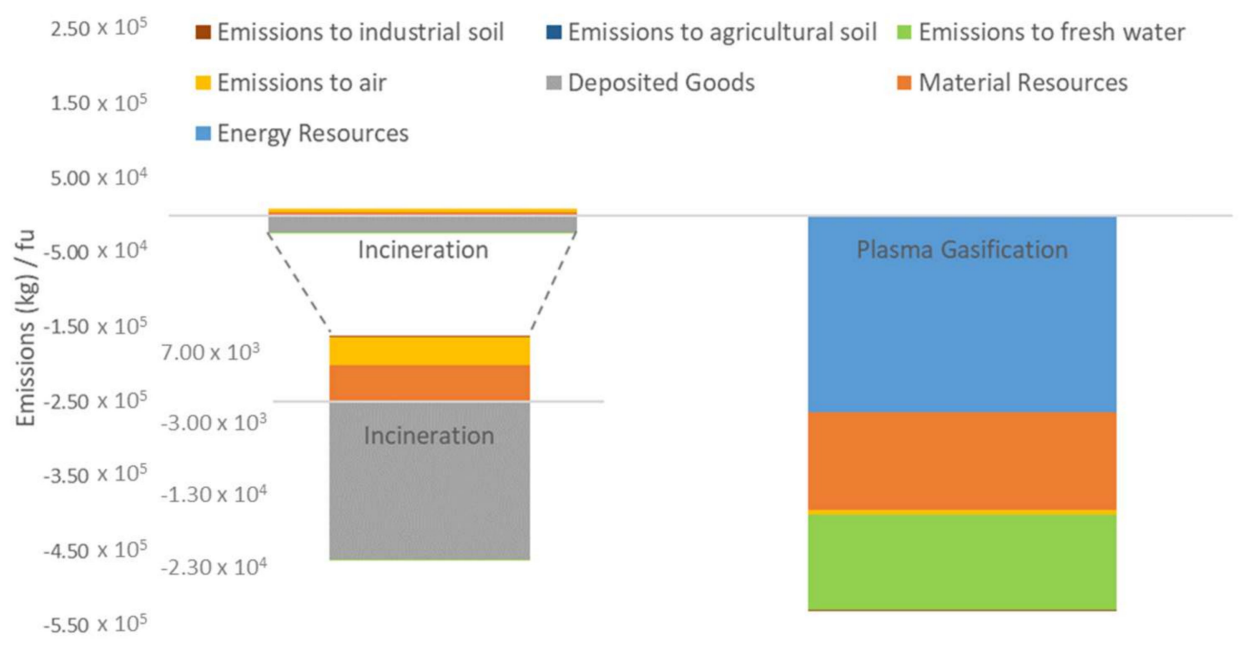

Figure 6. Environmental overall performance comparison between incineration and two-stage plasma gasification of one ton of MSW.

As an overall observation, it can be seen that plasma gasification is a more sustainable option, as its environmental profile displays negative values for all the emissions assessed, while conventional incineration presents some positive impacts. This means that, as a waste treatment, two-stage plasma gasification portrays environmental credits, in this specific case saving up to 260 tons of energy resources, 130 tons of material resources and similar amount of emissions to fresh water as main flows. On the other hand, incineration of a similar sample of MSW accomplishes an avoided burden of more than 20 tons of deposited goods, however, with an environmental hazard of 5 tons of material resources and 4 tons of emissions to air. Evangelisti et al. [49] have also shown the overall excellent performance of a two-stage gasification plasma treatment for MSW, establishing it as a better environmental solution than other available technologies. Several explanations may be drawn to support this outcome. One of the main reasons relies on the fact that in a two-stage plasma gasification facility, electricity is generated from the combustion of a high-quality syngas, which produces a high temperature gas that is send to a gas engine, whereas in the case of incineration, the flue gas resulting from the combustion process generates steam, afterwards utilized in a steam turbine to produce electricity, in inferior conditions. Another possible cause subscribing to these outputs may be the higher amount of metals withdrawn from the plasma gasification facility rather than smaller yields recovered from the bottom ashes at the incineration plant. Lastly, another approach contributing to the two-stage plasma gasification improved environmental profile may be the reduced air pollution control deposits removed from the system, when compared to the amount of these residues achieved with other WtE techniques.

In an attempt to understand the real cause for incineration performance, an assessment of the results for the individual impact categories contributing to the positive values of the environmental profile was established (not shown here). It is no surprise that, within other parameters, GWP seems to be the most influent indicator with values above $400 \mathrm{~kg} \mathrm{CO}_{2}$-equivalent for the incineration scenario versus (-)31 $\mathrm{kg} \mathrm{CO}$-equivalent for the two-stage plasma gasification. This is especially related to the carbon dioxide emissions, not only in the incineration process itself, but also during other processes of the system where higher amounts of auxiliary materials are required, when compared to plasma gasification, such as syngas treatment steps. The life cycle perspective takes in account all the inputs and outputs needed for the production of these materials, which afterwards depict a significant contribution to global warming potential [45]. Additionally, gasification occurs in a sub-stoichiometric oxygen atmosphere, which affords lower $\mathrm{CO}_{2}$ emissions than incineration [8]. These oxygen-starved conditions promote lower gas yields than incineration, maximizing the cleaning process [31]. Furthermore, this lower gas amount promotes less off-gas emissions and even less landfill necessities. 


\subsubsection{Efficiency Comparison}

The goal of this evaluation was to discuss the efficiency differences between standard incineration and the two-stage plasma gasification; this was done by resourcing to three distinct parameters: waste reduction (in mass \%), energy production (in GJ) and residues generation (in $\mathrm{kg}$ ). Figure 7 portrays the comparative assessment.

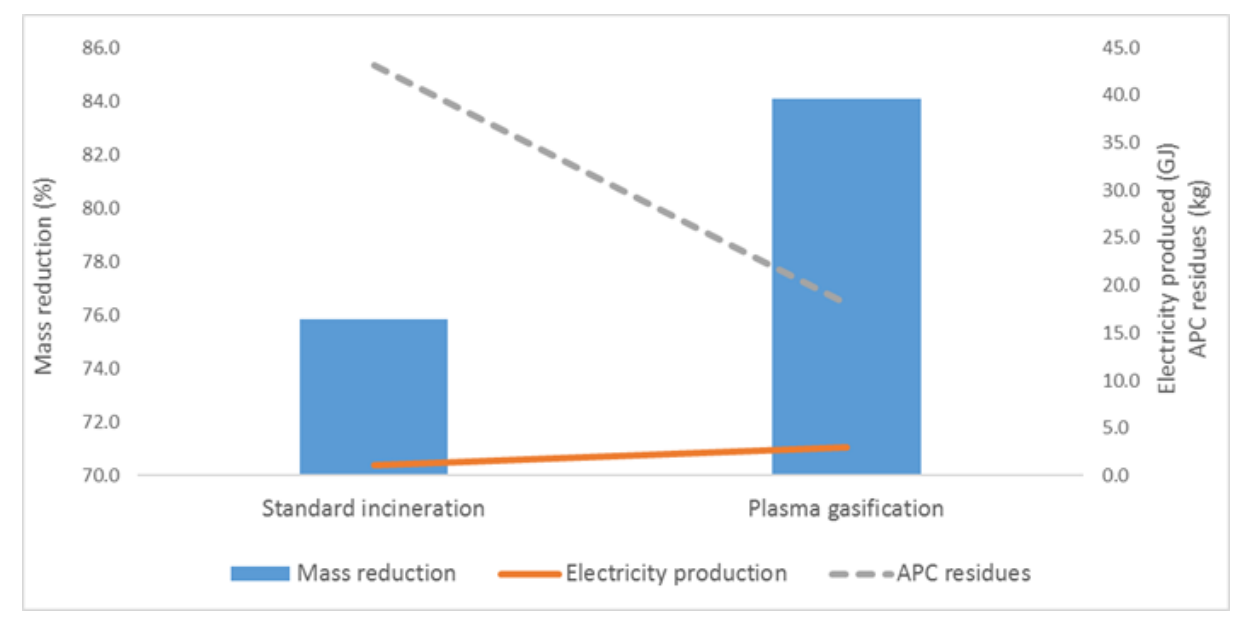

Figure 7. Efficiency performance comparison between incineration and two-stage plasma gasification of one ton of MSW.

As can be seen from Figure 7, standard incineration encloses a lower waste reduction (approximately $76 \%$ ), plasma gasification achieving an almost $10 \%$ higher result for this category. Additionally, when considering the formation of air pollution control (APC) residues, two-stage plasma gasification afforded better results again, producing only $15 \mathrm{~kg}$ of residues per ton of treated MSW, while incineration originated more than $40 \mathrm{~kg}$. Therefore, a typical incineration plant seems to constitute a poorer option concerning waste disposal, when compared to the two-stage plasma gasification assessed in this study.

As far as electricity production is concerned, plasma gasification showed a more efficient performance: a 2.7-fold higher outcome when compared to incineration. Lombardi et al. [28] reported the same conclusion when comparing plasma gasification energetic performance to more traditional WtE options, especially in the case where an internal combustion engine/steam combined cycle is further utilized. In fact, the plasma gasification herein presented gave rise to approximately $3 \mathrm{GJ}$ of electricity per ton of MSW, similar to the predictions made by Pourali [26], who reported on the possibility of each ton of MSW producing 3.24 GJ of electricity, enhanced to $4.32 \mathrm{GJ}$ if cogeneration was utilized. Furthermore, when compared to the net power output results for a compilation of plasma technologies accomplished by Ruj and Ghosh [36], our two-stage plasma gasification afforded even higher outcomes than the referred industrial processes (which ranged from $1.62 \mathrm{GJ}$ to $2.22 \mathrm{GJ}$ per ton of MSW treated). This is a very important feature to take in account when considering the choice of a WtE technique, as the ultimate aim of this waste disposal method is to convert the initial inputs into energy, which was successfully attained by the plasma gasification herein presented.

\section{Conclusions}

A life cycle analysis of the two-stage plasma gasification of one ton of municipal solid wastes confirmed this technologically advanced WtE procedure as environment friendly and sustainable. All the environmental categories assessed depicted negative values, meaning environmental benefits in terms of natural resources savings and also reduced pollutant emissions. GWP ( $-31 \mathrm{~kg} \mathrm{CO} 2$ eq.) and $\mathrm{EP}\left(-1.55 \times 10^{3} \mathrm{~kg} \mathrm{PO}_{4}{ }^{3-}\right.$ eq. $)$ values were better than reported in literature, while AP $\left(-39.7 \times 10^{-2} \mathrm{~kg} \mathrm{SO} 2\right.$ eq. $)$ and $\mathrm{POCP}\left(-2.23 \times 10^{-2} \mathrm{~kg}\right.$ ethene eq. $)$ values were similar or at least in 
the same order of magnitude. All the processes contributed to the global importance of this dual technique, even though the utilization of the electricity produced to feed the system itself (replacing part of the electrical grid mix share) and the high efficiency attained with plasma conversion were the main subscribers.

A comparison of the attained results to a conventional incineration plant shows that two-stage plasma gasification is a much more sustainable option, affording an overall improved performance. Through this technique, one ton of solid residues alleviates the environment in more than 2.5 tons of energy resources, 1.5 tons of material resources and one ton of emissions to freshwater. Meanwhile, incineration portrays environmental drawbacks especially regarding emissions to air and material resources. In what concerns waste reduction, two-stage plasma gasification proved to be a more effective disposal technique, additionally producing lower amounts of air pollution control residues. Relative to energy production, plasma gasification affords almost three times more electricity than standard incineration per ton of treated waste.

This study has shown that two-stage plasma gasification is a sustainable and clean WtE technique, proving to perform better in terms of environmental impacts than commonly used methods nowadays, furthermore, producing a significant yield of renewable energy. In fact, environmental issues (especially waste management and resource efficiency) are the key priorities of European Commission, as established by the General Union Environment Action Programme to 2020. Implementing WtE techniques such as the one herein described would doubly target this goal. On the one hand, the objective of reducing landfill sites would certainly be attained and, on the other, the energetic valorization of waste would substantially embody the resource efficiency topic. Additionally, the reduction in the greenhouse gas emissions portrayed by the two-stage plasma gasification reveals a portent strategy to abate the uncontrolled release of these gases to the environment.

Further work in this field would be to apply the LCA methodology to the plasma gasification of hazardous residues, such as medical waste, in order to understand if the range of benefits could be expanded to more concerning waste streams. Perhaps in this case, the chosen methodology should be such that more human-related impact categories are evaluated in order to adapt the conclusions to the context. Additionally, considering the enlargement of the system boundaries in order to include the impacts generated by the substitution of virgin materials for the vitrified agglomerate produced would be a valuable path to implement further this technology, creating an additional revenue to sustain the most demanding operations such as operation and management of the plasma torch. Indeed, one of the limitations of this work was that the established boundaries ended up being too strict to truly understand the cost/benefit relation of using the plasma torch, which proved to be the focal point of this work, due to the avoided emissions.

Supplementary Materials: The following are available online at http:/ /www.mdpi.com/1996-1073/12/1/137/s1. Supplementary Information 1: Mass and energy balances for the plasma gasification; Supplementary Information 2: Description refers to the European average incineration scenario.

Author Contributions: A.R. (Ana Ramos) conceived, designed and performed the experimental work, analyzed the data and wrote the paper. C.A.T. enabled and mentored the use of the LCA software. A.R. (Abel Rouboa) supervised the whole work. Conceptualization, A.R. (Ana Ramos); Methodology, A.R. (Ana Ramos) and C.A.T.; Software, C.A.T.; Supervision, A.R. (Abel Rouboa); Writing-original draft, A.R. (Ana Ramos).

Funding: This work was supported by the Portuguese Foundation for Science and Technology (grant number SFRH/BD/110787/2015).

Conflicts of Interest: The authors declare no conflict of interest. 


\section{Abbreviations}

$\begin{array}{ll}\text { ADP } & \text { abiotic depletion potential } \\ \text { AP } & \text { acidification potential } \\ \mathrm{APC} & \text { air pollution control } \\ \mathrm{CO}_{2} & \text { carbon dioxide } \\ \mathrm{DCB} & \text { dicholorobenzene } \\ \mathrm{EP} & \text { eutrophication potential } \\ \mathrm{FAETP} & \text { freshwater aquatic ecotoxicity potential } \\ \mathrm{GWP} & \text { global warming potential } \\ \mathrm{HTP} & \text { human ecotoxicity potential } \\ \text { LCA } & \text { life cycle assessment } \\ \text { LHV } & \text { lower heating value } \\ \mathrm{MAETP} & \text { marine aquatic ecotoxicity potential } \\ \mathrm{MSW} & \text { municipal solid waste } \\ \mathrm{NMVOC} & \text { non-methane organic volatile compounds } \\ \mathrm{NOx} & \text { nitrogen oxides } \\ \mathrm{ODP} & \text { ozone depletion potential } \\ \mathrm{PO}{ }_{4}^{3-} & \text { phosphate } \\ \mathrm{POCP} & \text { photochemical ozone creation potential } \\ \mathrm{R} 11 & \text { trichlorofluoromethane } \\ \mathrm{R} 114 & \text { dichlorotetrafluoroethane } \\ \mathrm{R} 12 & \text { dichlorodifluoromethane } \\ \mathrm{R} 22 & \text { chlorodifluoromethane } \\ \text { TETP } & \text { terrestrial ecotoxicity potential } \\ \text { WtE } & \text { Waste-to-Energy } \\ \mathrm{Sb} & \text { antimony } \\ \mathrm{SO}{ }_{2} & \text { sulphur dioxide }\end{array}$

\section{References}

1. Brems, A.; Baeyens, J.; Dewil, R. Recycling and recovery of post-consumer plastic solid waste in a European context. Thermal Sci. 2012, 16, 669-685. [CrossRef]

2. Pires, A.; Martinho, G.; Chang, N.-B. Solid waste management in European countries: A review of systems analysis techniques. J. Environ. Manag. 2011, 92, 1033-1050. [CrossRef] [PubMed]

3. Ryu, C.; Shin, D. Combined heat and power from municipal solid waste: Current status and issues in south korea. Energies 2012, 6, 45-57. [CrossRef]

4. Zhang, D.; Huang, G.; Xu, Y.; Gong, Q. Waste-to-energy in China: Key challenges and opportunities. Energies 2015, 8, 14182-14196. [CrossRef]

5. Reimann, D. CEWEP Energy Report-Status 2001-2004: Results of Specific Data for Energy, Efficiency Rates and Coefficients, Plant Efficiency Factors and NCV of 97 European WtE Plants and Determination of the Main Energy Results; CEWEP: Bamberg, Germany, 2005.

6. Fruergaard, T.; Hyks, J.; Astrup, T. Life-cycle assessment of selected management options for air pollution control residues from waste incineration. Sci. Total. Environ. 2010, 408, 4672-4680. [CrossRef] [PubMed]

7. Eriksson, O.; Finnveden, G. Energy Recovery from Waste Incineration-The Importance of Technology Data and System Boundaries on $\mathrm{CO}_{2}$ Emissions. Energies 2017, 10, 539. [CrossRef]

8. Zaman, A.U. Life cycle assessment of pyrolysis-gasification as an emerging municipal solid waste treatment technology. Int. J. Environ. Sci. Technol. 2013, 10, 1029-1038. [CrossRef]

9. Kumar, A.; Jones, D.D.; Hanna, M.A. Thermochemical Biomass Gasification: A Review of the Current Status of the Technology. Energies 2009, 2, 556-581. [CrossRef]

10. Sarker, S.; Arauzo, J.; Nielsen, H.K. Semi-continuous feeding and gasification of alfalfa and wheat straw pellets in a lab-scale fluidized bed reactor. Energy Convers. Manag. 2015, 99, 50-61. [CrossRef]

11. Tchapda, A.H.; Pisupati, S.V. A Review of Thermal Co-Conversion of Coal and Biomass/Waste. Energies 2014, 7, 1098-1148. [CrossRef] 
12. Zaccariello, L.; Mastellone, M.L. Fluidized-Bed Gasification of Plastic Waste, Wood, and Their Blends with Coal. Energies 2015, 8, 8052-8068. [CrossRef]

13. Bosmans, A.; Vanderreydt, I.; Geysen, D.; Helsen, L. The crucial role of waste-to-energy technologies in enhanced landfill mining: A technology review. J. Clean. Prod. 2013, 55, 10-23. [CrossRef]

14. Münster, M.; Meibom, P. Optimization of use of waste in the future energy system. Energy 2011, 36, 1612-1622. [CrossRef]

15. Lopes, E.J.; Okamura, L.A.; Yamamoto, C.I. Formation of dioxins and furans during municipal solid waste gasification. Braz. J. Chem. Eng. 2015, 32, 87-97. [CrossRef]

16. Tabasova, A.; Kropac, J.; Kermes, V.; Nemet, A.; Stehlik, P. Waste-to-energy technologies: Impact on environment. Energy 2012, 44, 146-155. [CrossRef]

17. Peng, N.; Li, Y.; Liu, Z.; Liu, T.; Gai, C. Emission, distribution and toxicity of polycyclic aromatic hydrocarbons (pahs) during municipal solid waste (msw) and coal co-combustion. Sci. Total Environ. 2016, 565, 1201-1207. [CrossRef] [PubMed]

18. Ray, R.; Taylor, R.; Chapman, C. The deployment of an advanced gasification technology in the treatment of household and other waste streams. Process Saf. Environ. Prot. 2012, 90, 213-220. [CrossRef]

19. Tang, L.; Huang, H.; Hao, H.; Zhao, K. Development of plasma pyrolysis/gasification systems for energy efficient and environmentally sound waste disposal. J. Electrost. 2013, 71, 839-847. [CrossRef]

20. Pfender, E. Thermal plasma processing in the nineties. Pure Appl. Chem. 1988, 60, 591-606. [CrossRef]

21. Benndorf, C.; Joeris, P.; Kroger, R. Mass and optical emission spectroscopy of plasmas for diamond synthesis. Pure Appl. Chem. 1994, 66, 1195-1205. [CrossRef]

22. Mollah, M.Y.A.; Schennach, R.; Patscheider, J.; Promreuk, S.; Cocke, D.L. Plasma chemistry as a tool for green chemistry, environmental analysis and waste management. J. Hazard. Mater. 2000, 79, 301-320. [CrossRef]

23. Kim, S.-W.; Park, H.-S.; Kim, H.-J. 100 kw steam plasma process for treatment of PCBs (polychlorinated biphenyls) waste. Vacuum 2003, 70, 59-66. [CrossRef]

24. Moustakas, K.; Fatta, D.; Malamis, S.; Haralambous, K.; Loizidou, M. Demonstration plasma gasification/vitrification system for effective hazardous waste treatment. J. Hazard. Mater. 2005, 123, 120-126. [CrossRef]

25. Ryan, T.P.; Stalder, K.R.; Woloszko, J. Overview of plasma technology used in medicine. SPIE BiOS 2013. [CrossRef]

26. Pourali, M. Application of Plasma Gasification Technology in Waste to Energy-Challenges and Opportunities. IEEE Trans. Sustain. Energy 2010, 1, 125-130. [CrossRef]

27. Ibrahimoglu, B.; Yilmazoglu, M.Z. Disposal of olive mill wastewater with DC arc plasma method. J. Environ. Manag. 2018, 217, 727-734. [CrossRef] [PubMed]

28. Lombardi, L.; Carnevale, E.; Corti, A. Analysis of energy recovery potential using innovative technologies of waste gasification. Waste Manag. 2012, 32, 640-652. [CrossRef]

29. Taylor, R.; Ray, R.; Chapman, C. Advanced thermal treatment of auto shredder residue and refuse derived fuel. Fuel 2013, 106, 401-409. [CrossRef]

30. Byun, Y.; Namkung, W.; Cho, M.; Chung, J.W.; Kim, Y.S.; Lee, J.H.; Lee, C.R.; Hwang, S.M. Demonstration of Thermal Plasma Gasification/Vitrification for Municipal Solid Waste Treatment. Environ. Sci. Technol. 2010, 44, 6680-6684. [CrossRef]

31. Helsen, L.; Bosmans, A. Waste-to-Energy through thermochemical processes: Matching waste with process. In Proceedings of the 1st International Symposium on Enhanced Landfill Mining, Houthalen-Helchteren, Belgium, 4-6 October 2010.

32. Tang, B.; Lin, J.; Qian, S.; Wang, J.; Zhang, S. Preparation of glass-ceramic foams from the municipal solid waste slag produced by plasma gasification process. Mater. Lett. 2014, 128, 68-70. [CrossRef]

33. Tagliaferri, C.; Evangelisti, S.; Clift, R.; Lettieri, P.; Chapman, C.; Taylor, R. Life cycle assessment of conventional and advanced two-stage energy-from-waste technologies for methane production. J. Clean. Prod. 2016, 129, 144-158. [CrossRef]

34. Pinto, F.; André, R.; Costa, P.; Carolino, C.; Lopes, H.; Gulyurtlu, I. Gasification Technology and Its Contribution to Deal with Global Warming, in Solid Biofuels for Energy; Springer: Berlin, Germany, 2011; pp. 151-175.

35. Materazzi, M.; Lettieri, P.; Mazzei, L.; Taylor, R.; Chapman, C. Thermodynamic modelling and evaluation of a two-stage thermal process for waste gasification. Fuel 2013, 108, 356-369. [CrossRef] 
36. Ruj, B.; Ghosh, S. Technological aspects for thermal plasma treatment of municipal solid waste-A review. Fuel Proc. Technol. 2014, 126, 298-308. [CrossRef]

37. Ducharme, C. Technical and Economic Analysis of Plasma-Assisted Waste-to-Energy Processes. Master's Thesis, Department of Earth and Environmental Engineering Fu Foundation of Engineering and Applied Science Columbia University September 2010 Research partially sponsored by the Earth Engineering Center. Columbia University, New York, NY, USA, 2010.

38. Liamsanguan, C.; Gheewala, S.H. Lca: A decision support tool for environmental assessment of msw management systems. J. Environ. Manag. 2008, 87, 132-138. [CrossRef] [PubMed]

39. ISO. Technical Committee ISO/TC 207, Environmental Management Subcommittee, Life cycle Assessment, Environmental Management: Life Cycle Assessment: Principles and Framework; ISO: Geneva, Switzerland, 2006.

40. Ramos, A.; Teixeira, C.A.; Rouboa, A. Environmental Analysis of Waste-to-Energy-A Portuguese Case Study. Energies 2018, 11, 548. [CrossRef]

41. Yadav, P.; Samadder, S.R. A critical review of the life cycle assessment studies on solid waste management in Asian countries. J. Clean. Prod. 2018, 185, 492-515. [CrossRef]

42. Wang, Z.; Ren, J.; Goodsite, M.E.; Xu, G. Waste-to-energy, municipal solid waste treatment, and best available technology: Comprehensive evaluation by an interval-valued fuzzy multi-criteria decision making method. J. Clean. Prod. 2018, 172, 887-899. [CrossRef]

43. Thinkstep, A.G. (Ed.) GaBi software-System and Database for Life Cycle Engineering; LBP-University of Stuttgart: Stuttgart, Germany, 1992-2016.

44. Chevalier, B.; Reyes, T.; Laratte, B. Methodology for choosing life cycle impact assessment sector-specific indicators. In Proceedings of the 18th International Conference on Engineering Design (ICED 11), Impacting Society through Engineering Design, DS 68-5, Lyngby/Copenhagen, Denmark, 15-19 August 2011; Volume 5: Design for X/Design to $\mathrm{X}$.

45. Stranddorf, H.; Hoffmann, L.; Schmidt, A. Impact Categories, Normalisation and Weighting in LCA (Påvirkningskategories, Normalisering og Vægtning I LCA-In Danish), Environmental News No. 78; The Danish Ministry of the Environment, Environmental Protection Agency: Copenhagen, Denmark, 2005.

46. Mountouris, A.; Voutsas, E.; Tassios, D. Plasma gasification of sewage sludge: Process development and energy optimization. Energy Convers. Manag. 2008, 49, 2264-2271. [CrossRef]

47. Eurostat, Eurostat-Statistics Explained. 2015. Available online: http://ec.europa.eu/eurostat/statisticsexplained/index.php/Municipal_waste_statistics (accessed on 5 January 2016).

48. Kulczycka, J.; Lelek, L.; Lewandowska, A.; Zarebska, J. Life cycle assessment of municipal solid waste management-Comparison of results using different Lca models. Pol. J. Environ. Stud. 2015, 24, 125-140. [CrossRef]

49. Evangelisti, S.; Tagliaferri, C.; Clift, R.; Lettieri, P.; Taylor, R.; Chapman, C. Life cycle assessment of conventional and two-stage advanced energy-from-waste technologies for municipal solid waste treatment. J. Clean. Prod. 2015, 100, 212-223. [CrossRef]

50. Evangelisti, S.; Tagliaferri, C.; Clift, R.; Lettieri, P.; Taylor, R.; Chapman, C. Integrated gasification and plasma cleaning for waste treatment: A life cycle perspective. Waste Manag. 2015, 43, 485-496. [CrossRef] [PubMed]

51. European Comission. "Eurostat-Statistics Explained." Electricity and Heat Statistics. Available online: https: / / ec.europa.eu/eurostat/statistics-explained/index.php?title=Electricity_and_heat_statistics (accessed on 19 June 2017).

52. European Commission. Directive 2000/76/EC of the European parliament and of the council. Off. J. Eur. Communities 2000, 332, 91-111.

(C) 2019 by the authors. Licensee MDPI, Basel, Switzerland. This article is an open access article distributed under the terms and conditions of the Creative Commons Attribution (CC BY) license (http://creativecommons.org/licenses/by/4.0/). 